\title{
Voltammetric behaviour of levodopa and its quantification in pharmaceuticals using a $\beta$-cyclodextrine doped poly (2,5-diaminobenzenesulfonic acid) modified electrode
}

\author{
MEHMET ASLANOGLU*, AYSEGUL KUTLUAY, SULTAN GOKTAS and \\ SERPIL KARABULUT \\ Department of Chemistry, University of Harran, Sanliurfa 63510, Turkey \\ e-mail: maslanoglu@harran.edu.tr; eurochemist $@$ hotmail.com
}

MS received 30 March 2008; revised 17 February 2009

\begin{abstract}
A cyclic voltammetric method based on a $\beta$-cyclodextrine doped poly(2,5-diaminobenzenesulfonic acid) modified glassy carbon electrode (GCE) was developed for the determination of levodopa. Compared with bare GCE and poly(2,5-diaminobenzenesulfonic acid)/GCE, the poly(2,5diaminobenzenesulfonic acid)- $\beta$-cyclodextrine/GCE exhibits a remarkable shift of the oxidation potentials of levodopa in the cathodic direction and a drastic enhancement of the anodic current response. The incorporation of $\beta$-cyclodextrine into the polymer film exhibited that the electrode provides more stable and sensitive current responses for levodopa. Levodopa exhibited a single broad peak at about $0.6 \mathrm{~V}$ at bare GCE. However, at the $\beta$-cyclodextrine doped poly(2,5-diaminobenzenesulfonic acid)/GCE, a well-defined redox wave of levodopa was obtained, with the oxidation and the reduction peak potential at $0 \cdot 193$ and $0 \cdot 164 \mathrm{~V}$, respectively. The separation of peak potentials was $29 \mathrm{mV}$. The linear current response was obtained in the range of $1.0 \times 10^{-6} \sim 2 \cdot 0 \times 10^{-4} \mathrm{M}$ with a detection limit of $4 \cdot 18 \times 10^{-7} \mathrm{M}$ for levodopa, The poly(2,5-diaminobenzenesulfonic acid)- $\beta$-cyclodextrine/GCE was also effective to simultaneously detect levodopa and ascorbic acid. The modified electrode has been successfully applied for the determination of levodopa in pharmaceuticals. The poly(2,5-diaminobenzenesulfonic acid)- $\beta$-cyclodextrine/GCE showed excellent stability and reproducibility.
\end{abstract}

Keywords. Levodopa; 2,5-diaminobenzenesulfonic acid; $\beta$-cyclodextrine; ascorbic acid; modified electrodes.

\section{Introduction}

Levodopa is an important chemical substance and used in the treatment of Parkinson's disease. This substance is known to be converted into dopamine by an enzymatic reaction for the deficiency of dopamine in brain. ${ }^{1}$

Several methods have been reported for the determination of levodopa including high performance liquid chromatography, ${ }^{2-4}$ flow injection analysis, ${ }^{5,6}$ gas chromatography, ${ }^{7}$ capillary zone electrophoresis, ${ }^{8-10}$ and spectrophotometry. ${ }^{11,12}$ Nevertheless, such methods are quite complicated since some of these methods need derivatization or combination with various detection methods. They also have low sensitivity and specificity.

However, electrochemical methods have been useful for the determination of electroactive species

\footnotetext{
*For correspondence
}

in pharmaceuticals due to its simplicity and low cost. $^{13,14}$ But, in electrochemical detection of levodopa, voltammetric methods may suffer from low sensitivity and selectivity that leads to an inactive overpotential due to the irreversibility of its voltammetric behaviour. A number of articles have appeared in the literature to solve these problems. Of these articles, electrochemically modified electrodes show good electrocatalytic activity and stability towards the detection of levodopa. ${ }^{14,15}$ Teixeria et al also described an oxovonadium-salen film electrode, which exhibited good activity for the detection of levodopa ${ }^{16}$ However, no articles have appeared in literature for monitoring levodopa in the presence of ascorbic acid. The presence of ascorbic acid with levodopa possess the oxidation peak potentials close to that of levodopa results in the voltammetric response of levodopa being almost overlapped by that of ascorbic acid. In this work, we report cyclic voltammetric behaviour of levodopa at a bare GCE, poly 
(2,5-diaminobenzenesulfonic acid) modified GCE and a $\beta$-cyclodextrine doped poly(2,5-diaminobenzenesulfonic acid) modified GCE. The poly $(2,5-$ diaminobenzenesulfonic acid)- $\beta$-cyclodextrine/GCE was found to be electrocatalytically active towards the oxidation of levodopa. The poly(2,5-diaminobenzenesulfonic acid)- $\beta$-cyclodextrine/GCE has been shown to be much better than poly(2,5-diaminobenzenesulfonic acid) modified GCE in terms of selectivity, stability and recovery for the determination of levodopa in pharmaceuticals as well as providing sensitive peak currents for levodopa. The proposed method has been successfully applied for the determination of levodopa in pharmaceutical formulations.

\section{Experimental}

\subsection{Chemicals and instrumentation}

Levodopa obtained from Fluka (Germany) was used as received. 2,5-diaminobenzenesulfonic acid, $\beta$ cyclodextrine and ascorbic acid were also purchased from Fluka (Germany). Medopar tablets containing levodopa were purchased from the local pharmacy. Solutions of 2,5-diaminobenzenesulfonic acid and $\beta$-cyclodextrine were prepared in $0.2 \mathrm{M} \mathrm{KCl}$ at $\mathrm{pH}$ 7.4. All other reagents were of analytical grade or equivalent, and obtained from Merck or Fluka. Solutions of levodopa and ascorbic acid were prepared in $0 \cdot 1 \mathrm{M}$ phosphate buffer solution (PBS) at $\mathrm{pH} 7 \cdot 2$. Aqueous solutions were prepared with doubly distilled water. Oxygen-free nitrogen was bubbled through the cell prior to each experiment. All experiments were carried out at ca. $25^{\circ} \mathrm{C}$. Electrochemical experiments were performed using an EcoChemie Autolab PGSTAT 12 potentiostat/galvanostat (Utrect, The Netherlands) with the electrochemical software package 4.9 or an Epsilon potentiostat (Bioanalytical Systems, Lafayette, USA) with the electrochemical software 1.6.70_XP. A three-electrode system was used: a glassy carbon electrode as working electrode [ $3 \mathrm{~mm}$ in diameter (Bioanalytical Systems, Lafayette, USA)], a Pt wire counter electrode and an $\mathrm{Ag} / \mathrm{AgCl}$ reference electrode.

\subsection{Preparation of modified glassy carbon electrodes}

Prior to electrochemical modification, the bare GCE was polished with $0.05 \mu \mathrm{m}$ alumina slurry on a pol- ishing pad. Then it was rinsed with water, and sonicated with $1+1 \mathrm{HNO}_{3}$ and acetone, and water for $10 \mathrm{~min}$, respectively. After being cleaned, the electrode was activated by 5 cyclic sweepings from $-0 \cdot 6$ to $+0.8 \mathrm{~V}$ in PBS at $\mathrm{pH} \mathrm{7.2.} \mathrm{Then,} \mathrm{the} \mathrm{electrode} \mathrm{was}$ immersed in a solution of $10 \mathrm{mM}$ 2,5-diaminobenzenesulfonic acid and $10 \mathrm{mM} \beta$-cyclodextrine dissolved in $0.2 \mathrm{M} \mathrm{KCl}$ at $\mathrm{pH} 7.4$ and was conditioned by cyclic sweepings from -1.5 to $+2.0 \mathrm{~V}$ for 10 scans. Afterwards, the modified electrode was electroactivated by cyclic voltammetry from -0.6 to $+0.8 \mathrm{~V}$ at $50 \mathrm{mV} / \mathrm{s}$ in $0.1 \mathrm{M}$ PBS at $\mathrm{pH} 7.2$. Figure 1 exhibits cyclic voltammograms of the $\operatorname{poly}(2,5-$ diaminobenzenesulfonic acid)- $\beta$-cyclodextrine/GCE in the range of $-0.6 \mathrm{~V}$ to $0.8 \mathrm{~V}$ at various scan rates in $0.1 \mathrm{M}$ PBS at $\mathrm{pH} 7 \cdot 2$. A pair of redox peaks, which are clearer at high scan rates, was obtained in each voltammogram. The anodic peak current (Ipa) was proportional to the scan rates over the range 50$250 \mathrm{mV} / \mathrm{s}$. Therefore, a surface controlled process played a more important role in the electrochemical process.

\subsection{Voltammetric assay of levodopa in tablets}

Five tablets were weighed and crushed to a fine powder in a mortar. A mass of powder equivalent to the average mass of one tablet was dissolved in $50 \mathrm{ml}$ of $0 \cdot 1 \mathrm{M}$ PBS at $\mathrm{pH} 7 \cdot 2$. It was then introduced to an ultrasonic bath for $5 \mathrm{~min}$, filtered and diluted with $0 \cdot 1 \mathrm{M}$ PBS in a calibrated $100 \mathrm{ml}$ flask. Appropriate dilutions were made from the super-

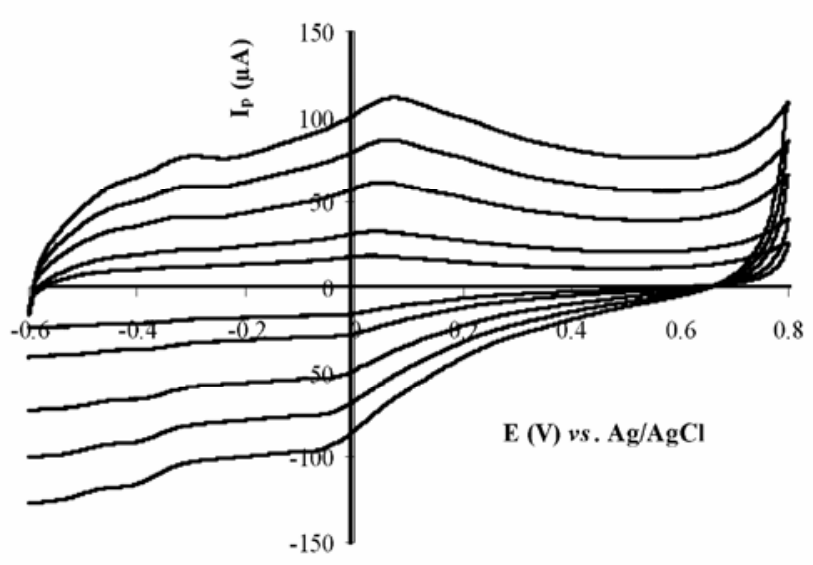

Figure 1. Cyclic voltammograms of poly(2,5-diaminobenzenesulfonic acid)- $\beta$-cyclodextrine/GCE in $0 \cdot 1 \mathrm{M}$ PBS at $\mathrm{pH} 7 \cdot 2$. Scan rates increasing from 50 to $250 \mathrm{mV} / \mathrm{s}$. Equilibrium time: $5 \mathrm{~s}$. 
natant solution with $0 \cdot 1 \mathrm{M}$ PBS. Then the tablet solution was subjected to cyclic voltammetry using the modified electrode. The content of drug was determined referring to the regression equation.

\section{Results and discussion}

\subsection{Voltammetric behaviour of levodopa}

Figure 2 exhibits the cyclic voltammograms of levodopa at (a) bare glassy carbon electrode (GCE), (b) poly(2,5-diaminobenzenesulfonic acid)/GCE and (c) $\operatorname{poly}(2,5$-diaminobenzenesulfonic acid)- $\beta$ cyclodextrine/GCE in $0 \cdot 1 \mathrm{M}$ PBS at $\mathrm{pH} 7 \cdot 2$. Levodopa exhibited a single broad peak at about $0.6 \mathrm{~V}$ at bare GCE. At poly(2,5-diaminobenzenesulfonic acid)/GCE a poor redox wave of levodopa was obtained. However, at the $\beta$-cyclodextrine doped poly (2,5-diaminobenzenesulfonic acid)/GCE, a welldefined redox wave of levodopa was obtained, with the oxidation and the reduction peak potential at $0 \cdot 193$ and $0 \cdot 164 \mathrm{~V}$, respectively. The separation of peak potentials was $29 \mathrm{mV}$. Furthermore, another reduction was observed at $-0.239 \mathrm{~V}$ as the initial potential of scanning shifted negatively. Compared with bare GCE and poly(2,5-diaminobenzenesulfonic acid)/GCE, $\beta$-cyclodextrine doped poly (2,5-diaminobenzenesulfonic acid)/GCE has increased the electron transfer properties of levodopa. Intensive increase in peak current is observed owing to the improvement in the reversibility of electron transfer process and the larger real area of the poly-

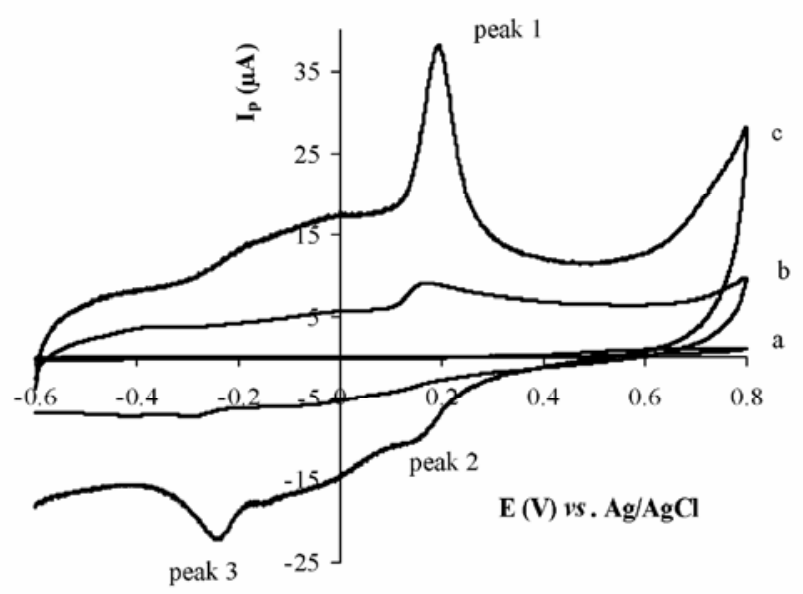

Figure 2. Cyclic voltammograms of $2.00 \times 10^{-5} \mathrm{M}$ levodopa at (a) bare GCE, (b) poly(2,5-diaminobenzenesulfonic acid)/GCE and (c) poly(2,5-diaminobenzenesulfonic acid)- $\beta$-cyclodextrine/GCE in $0 \cdot 1 \mathrm{M}$ PBS at $\mathrm{pH}$ 7.2. Equilibrium time: $5 \mathrm{~s}$, scan rate: $50 \mathrm{mV} / \mathrm{s}$. mer film. This suggests an efficient oxidation reaction toward levodopa at the poly(2,5-diaminobenzenesulfonic acid)- $\beta$-cyclodextrine/GCE.

The electrochemical behaviour of levodopa at poly(2,5-diaminobenzenesulfonic acid)- $\beta$-cyclodextrine/GCE might be represented as follows: peak (1) results from the oxidation of levodopa, which is a two-electron transfer process to produce levodopaquinone (reaction 1). Peak (2) appears by the reduction of levodopaquinone to levodopa (reaction 1). Peak (3) corresponds to formation of leucolevodopachrome resulting from the ring closure of levodopaquinone which contains an electron-deficient ring (reaction 2). The behaviour of levodopa at poly (2,5-diaminobenzenesulfonic acid)- $\beta$-cyclodextrine/ GCE is an electrochemical-chemical (EC) process. ${ }^{17}$ The proposed levodopa reactions are given in scheme 1.

To investigate the electrochemical process of levodopa at the modified electrode, the effect of scan rate on the electrochemical response of levo-

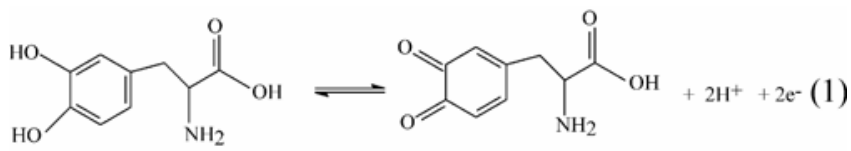<smiles>CCCCC(=O)O</smiles>

Scheme 1. Proposed levodopa reaction at poly $(2,5-$ diaminobenzenesulfonic acid)- $\beta$-cyclodextrine/GCE in $0 \cdot 1 \mathrm{M}$ PBS at $\mathrm{pH} 7 \cdot 2$.

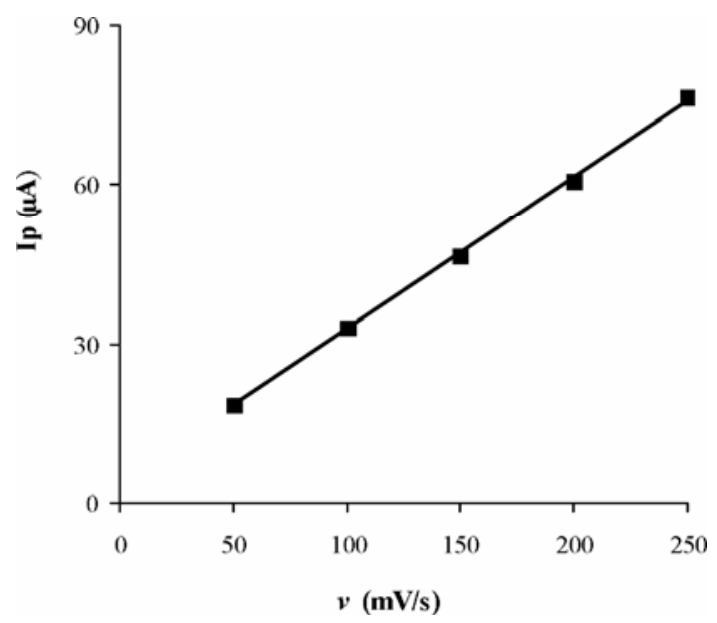

Figure 3. A plot of peak currents versus scan rates of $2 \cdot 00 \times 10^{-5} \mathrm{M}$ levodopa in $0 \cdot 1 \mathrm{M}$ PBS at $\mathrm{pH} 7.2$. 
dopa at poly(2,5-diaminobenzenesulfonic acid)- $\beta$ cyclodextrine/GCE using cyclic voltammetry in $0 \cdot 1 \mathrm{M}$ PBS at $\mathrm{pH} 7.2$ were carried out. The anodic peak current (Ipa) was proportional to the scan rate (v) over the range of $50-250 \mathrm{mV} / \mathrm{s}$ (figure 3 ). No shifts in the oxidation peak potential of levodopa were observed with increasing scan rate. The results indicated that the electrochemical oxidation of levodopa at poly(2,5-diaminobenzenesulfonic acid)$\beta$-cyclodextrine/GCE is a surface-controlled process.

In addition, the effect of the $\mathrm{pH}$ value of the PBS buffer solution on peak potential of levodopa at poly (2,5-diaminobenzenesulfonic acid)- $\beta$-cyclodextrine/ GCE was also investigated. The anodic peak potential of levodopa shifted in the negative direction with increasing $\mathrm{pH}$. This shows that the redox couple of levodopa includes proton transfer in the electrochemical processes. The slope of the plot of peak potential of levodopa versus $\mathrm{pH}$ value of its solution was $c a .57 .5 \mathrm{mV} / \mathrm{pH}$ (figure 4). This indicated that the proportion of the electron and proton involved in the reactions is $1: 1$. Since equal numbers of electrons and protons should be involved in the electrode reaction, the number of hydrogen ions involved in the whole electrode reaction is 2 .

\subsection{Calibration equation for the determination of levodopa}

Determination of the concentration of levodopa at poly(2,5-diaminobenzenesulfonic acid)- $\beta$-cyclodex-

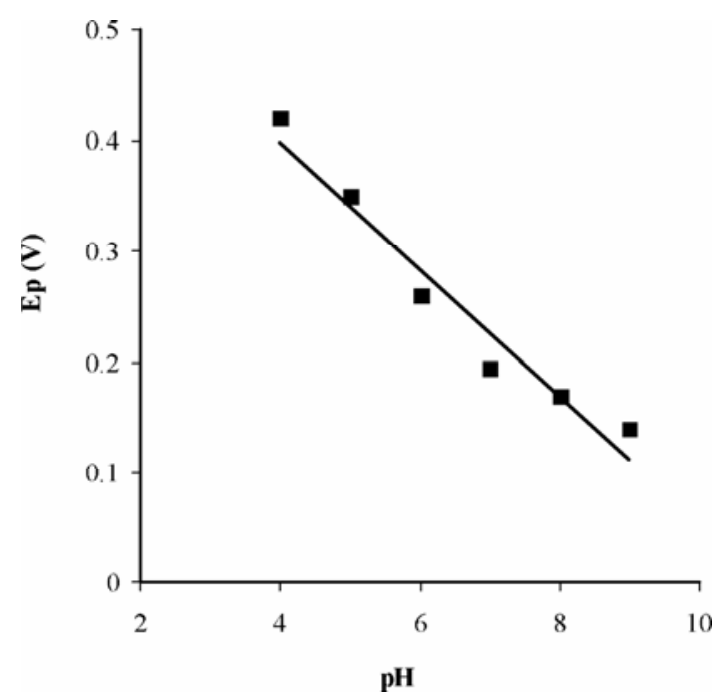

Figure 4. A plot of peak potential versus $\mathrm{pH}$ of the solution.
trine/GCE was performed at $\mathrm{pH} 7 \cdot 2$. The anodic peak currents were plotted against the bulk concentration of levodopa after the background subtraction (figure 5). The response of anodic peak currents of levodopa at poly(2,5-diaminobenzenesulfonic acid)$\beta$-cyclodextrine/GCE was linear with the concentration of levodopa in the range of $1.0 \times 10^{-6} \sim 2.0 \times$ $10^{-4} \mathrm{M}$. The linear regression equation was Ipa $(\mu \mathrm{A})=0.83685+0.92559 \mathrm{C}(\mu \mathrm{M})$ with a correlation coefficient of 0.9991 . The detection limit was $4 \cdot 18 \times 10^{-7} \mathrm{M}(\mathrm{S} / \mathrm{N}=3)$.

\subsection{Selective detection of levodopa in the presence of ascorbic acid}

Ascorbic acid which coexists in samples can be easily oxidized at a potential rather close to that of levodopa using a conventional electrode resulting in electrochemical response of levodopa being overlapped by that of ascorbic acid always interfere with the measurement of levodopa. In this work, it was found that this problem could be eliminated using poly(2,5-diaminobenzenesulfonic acid)- $\beta$-cyclodextrine/GCE. The cyclic voltammograms of the mixture of levodopa and ascorbic acid at bare GCE, poly(2,5-diaminobenzenesulfonic acid)/GCE and the $\beta$-cyclodextrine doped poly(2,5-diaminobenzenesulfonic acid)/GCE are given in figure 6 . At bare GCE, a single broad peak was observed for the mixture of AA and levodopa. However, two poor voltammetric peaks were obtained at poly $(2,5-$ diaminobenzenesulfonic acid)/GCE. Also, the potential separation between AA and levodopa is not con-

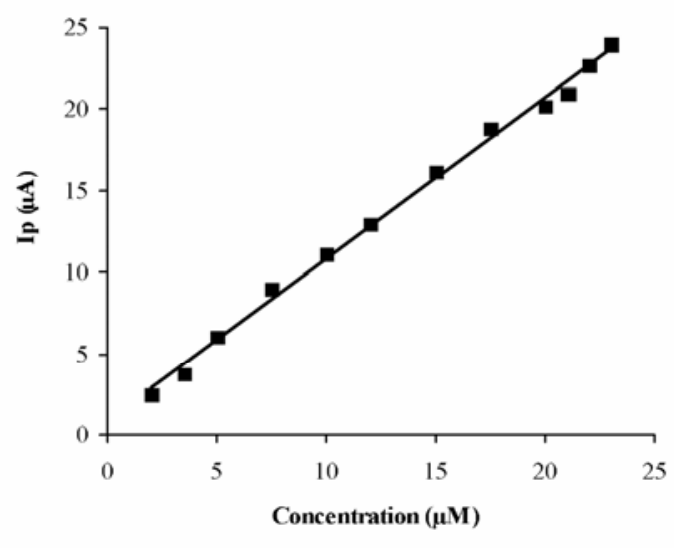

Figure 5. A plot of peak currents versus the increasing concentration of levodopa at poly(2,5-diaminobenzenesulfonic acid)- $\beta$-cyclodextrine/GCE. Equilibrium time: $5 \mathrm{~s}$, scan rate: $50 \mathrm{mV} / \mathrm{s}$. 
venient for the simultaneous determination. Compared to the bare GCE and poly(2,5-diaminobenzenesulfonic acid)/GCE, two sharp and welldefined cyclic voltammetric peaks were obtained at poly(2,5-diaminobenzenesulfonic acid)- $\beta$-cyclodextrine/GCE. The two peaks observed at $0.015 \mathrm{~V}$ and $0.193 \mathrm{~V}$ in $\mathrm{CV}$ correspond to the oxidation of ascorbic acid and levodopa, respectively.

It is clearly seen in figure 6 that the peak separation between ascorbic acid and levodopa is more appropriate and favourable at poly(2,5-diaminobenzenesulfonic acid)- $\beta$-cyclodextrine/GCE. Figure 7

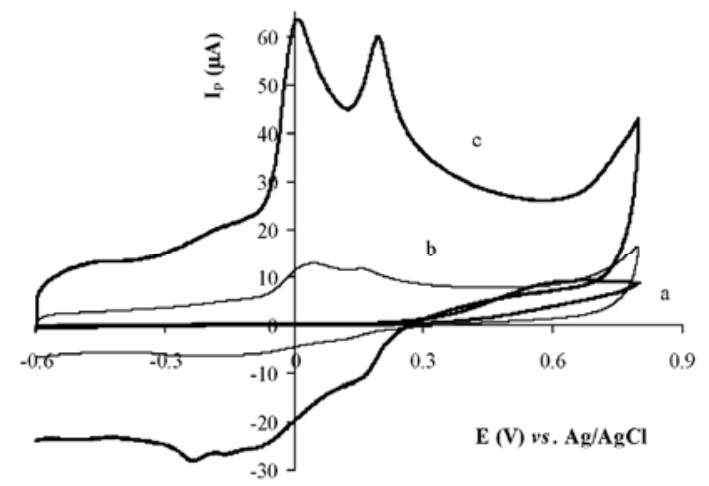

Figure 6. Cyclic voltammograms of the mixture of $3.00 \times 10^{-4} \mathrm{M}$ ascorbic acid and $3.75 \times 10^{-5} \mathrm{M}$ levodopa at (a) bare GCE, (b) poly(2,5-diaminobenzenesulfonic acid)/GCE and (c) poly(2,5-diaminobenzenesulfonic acid)- $\beta$-cyclodextrine/GCE in $0 \cdot 1 \mathrm{M}$ PBS at $\mathrm{pH} 7 \cdot 2$. Equilibrium time: $5 \mathrm{~s}$, scan rate: $50 \mathrm{mV} / \mathrm{s}$.

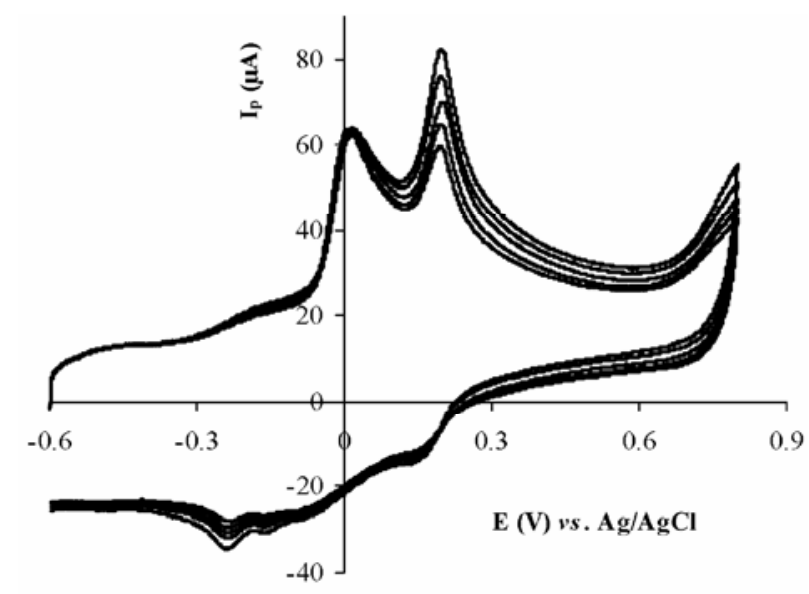

Figure 7. Cyclic voltammograms of the mixture of $3.00 \times 10^{-4} \mathrm{M}$ ascorbic acid and increasing concentrations of levodopa at poly(2,5-diaminobenzenesulfonic acid)- $\beta$ cyclodextrine/GCE in $0 \cdot 1 \mathrm{M}$ PBS at $\mathrm{pH} 7 \cdot 2$. Levodopa concentrations: (a) $3.75 \times 10^{-5} \mathrm{M}$, (b) $4.25 \times 10^{-5} \mathrm{M}$, (c) $4.75 \times 10^{-5} \mathrm{M}$, (d) $5.25 \times 10^{-5} \mathrm{M}$ and (e) $6.00 \times 10^{-5} \mathrm{M}$. Equilibrium time: $5 \mathrm{~s}$, scan rate: $50 \mathrm{mV} / \mathrm{s}$. represents the $\mathrm{CV}$ recordings at various concentrations of levodopa where concentration of ascorbic acid was kept constant. In the presence of ascorbic acid, the anodic peak current of levodopa increased linearly with the increase in its concentration. It is remarkable that excess amount of ascorbic acid does not interfere with the determination of levodopa. Overall facility of the poly(2,5-diaminobenzenesulfonic acid)- $\beta$-cyclodextrine/GCE for simultaneous determination of ascorbic acid and levodopa was demonstrated by simultaneously changing the concentration of ascorbic acid and levodopa. Figure 8 depicts the cyclic voltammograms that were obtained for levodopa and ascorbic acid coexisting at various concentrations. This indicates that the poly(2,5-diaminobenzenesulfonic acid)- $\beta$-cyclodextrine/GCE enables the simultaneous determination of levodopa and ascorbic acid. It is clear that the proposed method enables the detection of levodopa in the presence of ascorbic acid.

\subsection{Analytical applications}

The proposed method was utilized for the determination of levodopa in drug samples. Levodopa

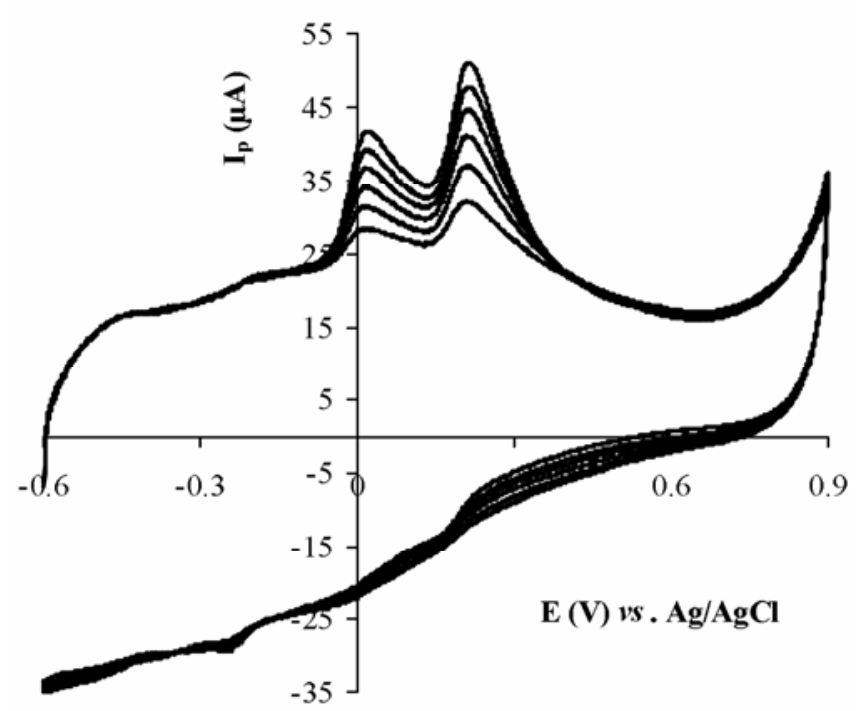

Figure 8. Cyclic voltammograms of the increasing concentrations of ascorbic acid and levodopa at poly(2,5diaminobenzenesulfonic acid)- $\beta$-cyclodextrine/GCE in $0 \cdot 1 \mathrm{M}$ PBS at $\mathrm{pH} 7 \cdot 2$. Ascorbic acid concentrations: $3.75 \times 10^{-5} \mathrm{M}$, (b) $6.50 \times 10^{-5} \mathrm{M}$, (c) $8.50 \times 10^{-5} \mathrm{M}$, (d) $1.10 \times 10^{-4} \mathrm{M}$, (e) $1.25 \times 10^{-4} \mathrm{M}$ and (f) $1.50 \times 10^{-4} \mathrm{M}$. Levodopa concentrations: (a) $7.50 \times 10^{-6} \mathrm{M}$, (b) $1.25 \times$ $10^{-5} \mathrm{M}$, (c) $1.75 \times 10^{-5} \mathrm{M}$, (d) $2.25 \times 10^{-5} \mathrm{M}$, (e) $2.5 \times$ $10^{-5} \mathrm{M}$ and (f) $2.75 \times 10^{-5} \mathrm{M}$. Equilibrium time: $5 \mathrm{~s}$, scan rate: $50 \mathrm{mV} / \mathrm{s}$. 
Table 1. Analysis of levodopa tablets.

\begin{tabular}{cccccc}
\hline & Content (mg) & Found (mg) & Recovery (\%) & RSD (\%) & Ref. (10) \\
\cline { 2 - 6 } Levodopa & 125 & $123.5 \pm 2.29$ & 98.8 & 1.85 & $99.3 \pm 2.94$ \\
\hline
\end{tabular}

Mean \pm standard deviation $(n=5)$

Table 2. Analysis of ascorbic acid injections

\begin{tabular}{lcccc}
\hline & Content $(\mathrm{mg})$ & Added (mg) & Found (mg) & Recovery (\%) \\
\cline { 2 - 5 } Ascorbic acid & 20 & 20 & $39.25 \pm 0.68$ & $98 \cdot 1$ \\
\hline
\end{tabular}

Mean \pm standard deviation $(n=5)$

tablets were dissolved in $0 \cdot 1 \mathrm{M}$ PBS at $\mathrm{pH} 7 \cdot 2$. The tablets were analysed by the standard addition method. The results are given in table 1 . The data obtained at poly(2,5-diaminobenzenesulfonic acid)$\beta$-cyclodextrine/GCE are in close agreement with the claimed values. The average recovery of $98.8 \%$ was obtained employing the proposed method. The data are also in good agreement with values obtained by the reported capillary electrophoresis method with a recovery of $99.3 \%{ }^{10}$ The average relative standard deviation (RSD) of $1.85 \%$ obtained from the proposed method is well compared with the relative standard deviations of $2.94 \%$ obtained from the previous studies of levodopa analysis. ${ }^{10}$ The results indicated that the proposed method could be easily used for the determination of levodopa. The validity of the proposed methods was also assured by the recovery of ascorbic acid (AA) in redoxan injections. The results of the AA injections are given in table 2 . The mean recovery of the five different measurements of the AA samples was $98.1 \%$ with an RSD of $1.73 \%$. The results indicated that the proposed method is accurate and sensitive.

\subsection{Selectivity, reproducibility and stability of the modified electrode}

Citrate, glucose, ascorbic acid and uric acid coexisting with levodopa were chosen for the study of selectivity of the proposed method. The effect of the interferents on the determination of levodopa was investigated. The results reveal that citrate, glucose, ascorbic acid and uric acid have no remarkable interference on the determination of levodopa.

The relative standard deviation (RSD) of 8 successive scans was $2.5 \%$ for $1.5 \times 10^{-5} \mathrm{M}$. This indicated that the reproducibility of the poly(2,5diaminobenzenesulfonic acid)- $\beta$-cyclodextrine/GCE was excellent. However, the modified electrode should be well treated to maintain its reproducibility. It was found that 20 cycles of scanning in $0 \cdot 1 \mathrm{M}$ PBS in the potential range $0.0 \sim 0.8 \mathrm{~V}$ could regenerate clean background $\mathrm{CV}$ curves and the modified electrode was ready for the next experiment or storage in $0.1 \mathrm{M}$ PBS. Also, the current response decreased only by $5 \sim 6 \%$ over a week for storage in $0 \cdot 1 \mathrm{M}$ PBS.

\section{Conclusions}

This study has indicated that $\beta$-cyclodextrine doped poly(2,5-diaminobenzenesulfonic acid)/GCE exhibits electrocatalytic activity to the oxidation of levodopa and provide voltammetric monitoring of levodopa in the presence of ascorbic acid. Compared with a bare GCE and poly(2,5-diaminobenzenesulfonic acid)/GCE, the poly(2,5-diaminobenzenesulfonic acid)- $\beta$-cyclodextrine/GCE exhibits a distinct shift of the oxidation potential of levodopa in the cathodic direction and a marked enhancement of the anodic current response. The poly(2,5-diaminobenzenesulfonic acid)- $\beta$-cyclodextrine/GCE has been shown to be much better than poly(2,5-diaminobenzenesulfonic acid) modified GCE in terms of selectivity, stability and recovery for the determination of levodopa in pharmaceuticals as well as providing sensitive peak currents for levodopa. The poly(2,5diaminobenzenesulfonic acid)- $\beta$-cyclodextrine/GCE has a good sensitivity and reproducibility.

\section{Acknowledgement}

The authors acknowledge the financial support from the Scientific and Technological Research Council of Turkey for a grant (Project No. 106T404). 


\section{References}

1. Weiner W J 2002 Parkinson's Disease: Diagnosis and Clinical Management, Demos (New York: Medical Publishing) p. 195

2. Kafil J B and Dhingra B S 1994 J. Chromatogr. A667 175

3. Rondelli I, Acerbi D, Mariotti F and Ventura P 1994 J. Chromatogr. B: Biomed. Appl. 65317

4. Tolokan A, Klebovich I, Balogh-Nemes K and Horavil G, 1997 J Chromatogr. B: Biomed. Appl. 698201

5. Pistonesi M, Centurion M E, Fernandez Band B S, Damiani P C and Olivieri A C 2004 J. Pharm. Biomed. Anal. 36541

6. Marcolino-Júnior L H, Teixeira M F S, Pereira A V and Fatibello-Filho O $2001 \mathrm{~J}$. Pharm. Biomed. Anal. 25393

7. Hansson C, Agrup G, Rorsman H and Rosengren A M 1979 J. Chromatogr. 1627

8. Zhang L, Chen G, Lu Q and Fang Y 2001 Anal. Chim. Acta 431287
9. Wang J, Zhou Y, Liang J, He P G and Fang Y Z 2005 Chromatographia $\mathbf{6 1} 265$

10. He W W, Zhou X W and Lu J Q 2007 Chinese Chem. Lett. 1891

11. Helaleh M I H, Rahman N and Abu-Nameh E S M 1997 Anal. Sci. 131007

12. Coello J, Maspoch S and Villegas N 2000 Talanta 53 627

13. Aslanoglu M and Peker N 2003 J. Pharm. Biomed. Anal. 331143

14. Quintino M S M, Yamashita M and Angnes L 2006 Electroanal. 18665

15. Teixeira M F S, Bergamini M F, Marques C M P and Bocchi N 2004 Talanta 631083

16. Teixeira M F S, Marcolino L H, Fatibello-Filho O, Dockal E R and Bergamini M F 2007 Sensors \& Actuators $B \mathbf{1 2 2} 549$

17. Bard A J and Faulkner L R 2001 Electrochemical Methods. Fundamentals and Applications (New York: John Wiley) 2nd edn 